\title{
Efeitos do Pronaf Sobre a Pobreza Rural no Brasil (2001-2009)
}

\author{
Henrique Rogê Batistaํㅜ e Henrique Dantas Neder²
}

Resumo: O objetivo deste trabalho é analisar os efeitos do Programa Nacional de Fortalecimento da Agricultura Familiar (Pronaf) sobre a pobreza rural (Índice FGT) no Brasil no período de 2001-2009. Para isto, são geradas estimativas das elasticidades (modelo de painel dinâmico: GMM-Sistema) Pronaf-renda e Pronafdesigualdade. $\mathrm{O}$ trabalho parte do pressuposto que a variável Pronaf não afeta diretamente a pobreza rural e o faz a partir da variação da renda e/ou da variação na desigualdade de renda. A revisão da literatura indica que o aumento na renda per capita ou o decréscimo no Índice de Gini levam a uma redução da pobreza e, além disto, não há um consenso entre o efeito da variação nos repasses do Pronaf sobre a renda, desigualdade e pobreza rural. Os resultados das estimativas para o rural brasileiro indicam que: i) a elevação da renda per capita ou o decréscimo da desigualdade de renda tendem a reduzir a pobreza; ii) o efeito do Pronaf sobre a renda per capita média e a desigualdade de renda está condicionado às especificidades socioeconômicas das unidades de observação e iii) os gastos do Pronaf tendem a reduzir indiretamente a pobreza via elevação da renda média e da redução da concentração de renda.

Palavras-chaves: Renda per capita, concentração de renda, Pronaf, pobreza rural.

Abstract: The objective of this work is to analyze the effects of National Program for Strengthening of Family Agriculture (Pronaf) in rural economic growth and income inequality in Brazil in the 2001-2009 period. For this, it is estimated (through dynamic panel model: GMM-System) income-Pronaf and inequality- Pronaf elasticities. The work assumes that the variable Pronaf does not directly affect poverty and it does so from the variation of income and/or changes in income distribution. The literature review indicated that an increase in per capita income and a decrease in the Gini coefficient lead to a reduction of rural poverty, and a positive change in Pronaf credits leads to an increase in per capita household income and a decrease in the income concentration. The estimates for rural Brazilian indicate that: i) the increase in per capita income or decrease in income inequality tend to reduce poverty; ii) the effect of Pronaf on the average per capita income and income inequality is conditioned by the socioeconomic specifics of observation units,

1. Doutorando em Economia pela Universidade de Brasília. E-mail: henriqueroge@hotmail.com

2. Professor Adjunto III da Universidade Federal de Uberlândia. E-mail: hdneder@ufu.br 
and iii) the expenses of Pronaf tend to indirectly reduce poverty by increasing the average income of farmers and reducing the income concentration.

Key-words: Per capita income, income distribution, Pronaf, rural poverty.

Classificação JEL: O15, I32, C33.

\section{Introdução}

A pobreza rural guarda suas especificidades frente à pobreza urbana sendo que o grau de vulnerabilidade das famílias pobres rurais tende a ser mais expressivo tanto pelo critério da renda, quanto no que se refere à dificuldade de acesso aos serviços básicos de saúde, educação, saneamento básico, dentre outros.

De acordo com Bourguignon (2004), a mitigação da pobreza seria possível por duas vias: i) através do crescimento do produto da economia que beneficiasse todas as camadas de renda da sociedade e ii) através do decréscimo da desigualdade de renda, que elevaria a renda dos mais pobres em detrimento dos ricos.

Neste contexto, evidências empíricas têm correlacionado negativamente as variáveis pobreza e crescimento econômico, e positivamente as variáveis pobreza e desigualdade de renda $(\mathrm{SON}$, 2003; ROCHA, 2006; CLINE, 2004; ZAULI, 2005; HOFFMANN, 2006). Além disso, a combinação entre crescimento e redução da desigualdade tem conduzido a resultados que apontam para um efeito maior sobre a mitigação da pobreza (ARAÚJO e MARINHO, 2012; ADAMS, 2002; ZAULI, 2005).

Considerando-se as políticas públicas no Brasil que podem ser relevantes no sentido de atenuar a pobreza, analisamos neste artigo o Programa Nacional de Fortalecimento da
Agricultura Familiar (Pronaf) criado em 1996 e coordenado pelo Ministério do Desenvolvimento Agrário (MDA) por meio da Secretaria de Agricultura Familiar (SAF). O Pronaf está estruturado tendo como objetivo financiar projetos individuais e coletivos que beneficiariam tanto os agricultores familiares quanto os assentados da reforma agrária. O programa é destinado às famílias rurais, com público alvo estabelecido segundo as diversas modalidades do programa, provenientes do estabelecimento rural ou não, que desenvolvem atividades rurais agropecuárias ou não agropecuárias visando a geração de renda e, consequentemente, melhoria na qualidade de vida (MDA, 2013).

Tendo isso em vista, o objetivo principal deste trabalho é analisar a relação existente entre o montante de crédito do Pronaf destinado aos agricultores familiares dos Grupos A, B e A/C (que compõem os grupos de agricultores familiares de menor renda) e a pobreza rural no País. A hipótese central é a de que o Pronaf afeta a pobreza através de dois mecanismos: 1) contribui para o aumento do rendimento médio dos pequenos agricultores familiares e 2 ) tende a reduzir a desigualdade de renda rural, na medida em que é direcionado aos agricultores de menor renda (Grupos A, B e A/C). A partir do efeito do Pronaf sobre estas duas variáveis (rendimento médio e concentração dos rendimentos), estabelece-se uma relação indireta com a redução da pobreza 
rural condicionada aos valores das elasticidades renda-pobreza e desigualdade-pobreza.

Para cumprir este objetivo, as elasticidades são estimadas a partir de um modelo econométrico de dados em painel com as Unidades Federativas correspondendo às unidades de análise no período de 2001 a 2009. As elasticidades são estimadas por meio do modelo econométrico dinâmico para dados em painel, com estimadores desenvolvidos por Arellano-Bond (1991), Arellano-Bover (1995) e Blundel-Bond (1998), com ênfase para o estimador GMM-Sistema.

Dado este objetivo, o trabalho está dividido em três seções, além desta introdução e das considerações finais. A seção dois apresenta dois breves levantamentos teóricos referentes à relação entre pobreza, desigualdade e crescimento e a relação entre o Pronaf e algumas variáveis socioeconômicas no rural. Na terceira seção, é descrito o modelo de dados em painel dinâmico pelo método de momentos generalizados para sistema em dois estágios, bem como o levantamento das estatísticas descritivas das variáveis dos modelos. Na quarta seção, são apresentados e discutidos os principais resultados das estimativas.

\section{Revisão bibliográfica}

Esta seção está dividida em duas partes: na primeira, é realizada uma discussão sobre a relação entre crescimento, desigualdade e pobreza e, na segunda, destaca-se brevemente o desenho institucional do Pronaf para, em seguida, discorrer-se sobre sua relação com as variáveis renda, produtividade, desigualdade de renda e a pobreza rural.

\subsection{Crescimento, desigualdade e pobreza}

Bourguignon (2002), a partir de um diagrama de distribuição de renda normal (formato de sino), em que a fração pobre da população é representada pela parcela com renda inferior à linha de pobreza, ilustrou que alterações neste diagrama resultam na alteração da densidade da renda e, consequentemente, da incidência da pobreza. Bourguignon (2002) constatou que a redução da pobreza poderia ser decomposta em dois efeitos: efeito renda e efeito distribuição. $\mathrm{O}$ efeito renda corresponde à mudança proporcional em todos os decis de renda sem alteração na renda relativa, o que levaria ao deslocamento, paralelo e para a direita, do diagrama de distribuição de renda (função densidade) reduzindo, consequentemente, a área abaixo desta função densidade correspondente à cauda à esquerda da linha de pobreza. O efeito distribuição, por sua vez, altera a renda relativa da população, mantendo constante a renda média, o que leva ao achatamento da curva de distribuição, que também contribui para o decréscimo da pobreza.

Desta forma, a mitigação da pobreza pode ser resultado da combinação de políticas voltadas para o crescimento do produto associado à redução da concentração de renda. Tal constatação deu origem à conhecida "relação triangular pobreza-crescimento-desigualdade" (BOURGUIGNON, 2004), em que a estratégia de desenvolvimento para uma dada região se daria pela combinação de tais políticas. Entretanto, a magnitude do efeito em reduzir a pobreza por estas duas vias (crescimento e desigualdade) guarda relação com as especificidades socioeconômicas de cada região.

Neste contexto, a relação triangular é sustentada pela correlação entre as variáveis: correlação negativa entre a pobreza e o crescimento econômico (ADAMS, 2002; GAFAR, 1998; BOURGUIGNON, 2002; DATT e RAVALLION, 1992) e correlação positiva entre a pobreza e a desigualdade de renda (ROCHA, 2006; CLINE, 2004; HOFFMANN, 2006). Neste contexto, tem ganhado proporção a quantidade de trabalhos empíricos voltados à constatação da relação triangular em vários países (DATT e RAVALLION, 1992; CHEN e WANG, 2001; CONTRERAS, 2003; ADAMS, 2004).

No Brasil, o elevado produto econômico paralelo à expressiva desigualdade de renda conduz a especificidades em tal relação triangular pobreza-crescimento-desigualdade. Destaca-se, neste 
caso, a importância dos valores das elasticidades estimadas, no qual a promoção da igualdade de renda tende a apresentar maior efeito em reduzir a pobreza quando comparado com a promoção do crescimento econômico.

Esta peculiaridade socioeconômica brasileira (elevado produto e desigualdade de renda) permite a coexistência de elevados níveis de pobreza e renda. De tal forma que o Brasil não é um país essencialmente pobre, mas a desigualdade na distribuição de renda e das oportunidades de inclusão econômica e social torna-se um dos principais determinantes da pobreza, dada a existência de recursos suficientes para erradicá-la (BARROS, HENRIQUES e MENDONÇA, 2000).

Neste sentido, a exemplo da década de 1970, a história econômica do Brasil provou que o crescimento não é suficiente em erradicar a pobreza. Trabalhos empíricos constataram que, apesar de o crescimento econômico guardar relação inversa com a situação de privação, não é "suficiente" em promover o padrão de vida da população. $\mathrm{Ou}$ seja, a manutenção de elevadas taxas de crescimento não garantiram que o bônus do crescimento fosse usufruído por toda população e, além disto, o efeito do crescimento sobre a pobreza pode ser potencializado quando combinado com um perfil distributivo mais equitativo (IPEA, 2011; ROCHA, 2006; NERI, 2006). Além disso, Hoffmann (2006) destaca que mesmo diante da ausência de crescimento econômico, a pobreza poderia ser reduzida como resultado de uma redução da concentração de renda.

Portanto, a estratégia para a redução da situação de privação do indivíduo guarda relação com as especificidades socioeconômicas da região. Estudos comprovam que em regiões mais pobres, as políticas voltadas para a promoção da renda, via elevação do produto econômico, tendem a ser mais eficientes para a redução da pobreza e, nas regiões ricas e desiguais, políticas distributivas provaram ter efeito mais expressivo sob o mesmo fim (BOURGUIGNON, 2002; TOCHETTO et al., 2004; ZAULI, 2005). Entretanto, apesar da heterogeneidade da incidência isolada destas duas políticas, a combinação entre elas implica na melhor estratégia em reduzir a densidade de pessoas na situação de pobreza (BOURGUIGNON, 2004; RAVALLION, 1997; RAVALLION, 2004; CASTELAR, TABOSA e IRFFI, 2013).

\subsection{Pronaf e pobreza}

Visando reduzir a pobreza e a desigualdade rural, além de romper com a exclusão das famílias rurais no acesso ao crédito, fruto do processo histórico de formação econômica do País, em 1995, o Programa de Valorização da Pequena Produção Rural (1994) foi criado no governo de Itamar Franco. Posteriormente, no governo de Fernando Henrique Cardoso, tal programa foi sujeito a reformulações que resultariam, por meio do Decreto no 1.946 , de 28 de junho de 1996, no Programa Nacional de Fortalecimento da Agricultura Familiar (Pronaf), cujo objetivo estaria baseado em "promover o desenvolvimento sustentável do segmento rural constituído pelos agricultores familiares, de modo a propiciar-lhes o aumento da capacidade produtiva, a geração de empregos e a melhoria de renda" (BRASIL, 1996). Por meio do voto no 103 do Conselho Monetário Nacional e a Resolução do Banco Central no 2.191, de 24 de agosto de 1995, foram determinadas as regras de financiamento do programa.

De acordo com o Manual de Crédito Rural (MDA, 2012), o Pronaf está estruturado em três modalidades de financiamento: i) crédito de custeio; ii) crédito de investimento e iii) integralização de Cotas-Partes de cooperados de cooperativas de produção de produtores rurais. A concessão do financiamento está associada a quatro objetivos: i) adaptar a política pública de acordo com a realidade socioeconômica dos agricultores familiares; ii) potencializar o desempenho produtivo dos agricultores por meio da melhoria da infraestrutura; iii) dar acesso da tecnologia e gestão social aos agricultores familiares e iv) aproximar os agricultores familiares aos mercados de insumo e produto.

O Pronaf é um programa que oferta crédito a produtores familiares destinados ao financiamento e custeio de projetos individuais ou coleti- 
vos. Esta modalidade de crédito conta com baixas taxas de juros quando comparadas com demais linhas de créditos rurais, e ainda apresenta maior carência para o início dos pagamentos, o que tem favorecido as baixas taxas de inadimplência.

Neste contexto, cabe destacar que a agricultura familiar corresponde a um importante segmento da economia brasileira, ocupando mais de $74 \%$ da população dos estabelecimentos rurais e gerando 38\% do valor total produzido pela agropecuária nacional (IBGE, 2009). O principal programa de crédito destinado a este segmento, o Pronaf, apresenta como uma das suas principais características, a partir de 2002, a utilização dos recursos disponíveis, ou seja, a expansão do volume aplicado. De 2002/03 a 2008/09, os recursos e o número total de contratos do programa elevaram-se de forma considerável: $454 \%$ e $53 \%$, respectivamente; sendo que cerca de $60 \%$ do total dos recursos foram destinados ao custeio das safras e $40 \%$, para o crédito de investimento (DELGADO, LEITE e WESZ, 2011).

Todavia, a aplicação dos recursos e contratos do Pronaf é heterogênea entre as regiões brasileiras e guarda contradições quando ao número de agricultores familiares em suas respectivas regiões. Em 2002, a maior parte dos recursos totais e contratos do Pronaf eram demandados pela região Sul, comportamento que se reverte nos anos seguintes, com ganho de participação da região Nordeste e, a partir de 2007, a tendência de reconcentração é retomada devido às alterações nas normas do programa. Desta forma, nos anos 2008/09, as participações observadas foram: região Sul com $52 \%$ dos recursos totais, $42 \%$ dos contratos e $20 \%$ das famílias rurais; região Nordeste com $16 \%$ dos recursos, $32 \%$ dos contratos e com quase metade dos agricultores familiares do País e região Sudeste com $20 \%$ dos recursos do Pronaf, $17 \%$ dos contratos e $16 \%$ da agricultura familiar (FERNANDES, 2011; DELGADO, LEITE e WESZ, 2011; MARTINS, ALENCAR e MENDONÇA, 2006; SOUZA, NEY e PONCIANO, 2010).

Outro ponto a ser ressaltado é a desigualdade de acesso aos recursos do Pronaf entre os grupos de agricultores familiares, sendo a maior fatia destinada aos grupos de maior renda e modernização. Esta concentração está fortemente associada à elevação do limite da renda bruta anual, para enquadramento de agricultor familiar do programa; desta forma, de 2002/3 a 2008/09, o Grupo A teve a sua participação nos recursos totais do programa reduzida de $20 \%$ para $5 \%$, o Grupo B manteve sua participação entre 7-8\%, o Grupo C variou de $30 \%$ para $20 \%$ e os Grupos D e E, os de maior renda bruta anual familiar, tiveram variações positivas de 16 pontos percentuais, atingindo 67\% dos recursos (FERNANDES, 2011; DELGADO, LEITE e WESZ, 2011; SILVA, CORREA e NEDER, 2007).

Hoffmann e Ney (2004) apontam a importância em oferecer o apoio à agricultura familiar diante do seu potencial em dinamizar a economia e compor uma forte estratégia de combate à desigualdade social e a pobreza rural. Segundo estes autores, a concentração de terra e renda observada principalmente na década de 1960 fez com que a desigualdade no País se tornasse cada vez mais difícil de ser superada. Isto se deve, sobretudo, ao fato de a concentração de terras e a concentração de rendimentos estarem fortemente e positivamente associadas.

O efeito social e econômico do Pronaf entre os agricultores familiares, entretanto, é controverso na literatura econômica. Pereira, Figueiredo e Loureiro (2004) e Kageyama (2003) constataram que o acesso ao crédito não guarda evidências com a elevação da renda, da redução da pobreza e do avanço da educação entre os agricultores familiares. Estes resultados apontam para a incapacidade do Pronaf frente aos seus objetivos e também foram constatados por Fecamp (2002) e Feijó (2001), que compararam um grupo de controle com um grupo de tratamento. Estes últimos autores constataram que os beneficiários do programa apresentaram renda média inferior ao grupo sem acesso e, sob a ótica da produtividade, os favorecidos pelo programa apresentaram crescimento de produtividade inferior ao grupo de controle.

Por outro lado, Ferraz et al. (2008) e Pucci (2009) apontam para conclusões distintas no que 
se refere à ineficiência do programa diante de seus objetivos. Segundo tais autores, as políticas de microcrédito e as taxas de juros mais reduzidas, quando direcionadas aos cidadãos de baixo poder econômico e em situação plena para honrar os compromissos com os pagamentos, correspondem a um mecanismo efetivo em viabilizar a realização de investimentos nas atividades produtivas e de enfrentamento da pobreza e miséria rural.

Sendo assim, o acesso ao crédito deve funcionar como um instrumento eficiente para a redução da pobreza. A importância do microcrédito não supre a necessidade do crédito tradicional, mas ainda assim atende parte das necessidades dos tomadores e, mesmo que moderadamente, busca reduzir os níveis de pobreza ao possibilitar o acesso ao mercado financeiro pelas famílias produtoras agrícolas de menor renda. Desta forma, permite elevar a renda, a produtividade e modernização de tais famílias, além de permitir o investimento e inovação na agricultura familiar (KUHR, 2004; CLAESSENS e PEROTTI, 2004; ABRAMOVAY, 2004; MATTEI, 2005).

Algumas evidências empíricas constataram que uma das mais notórias repercussões sociais do Pronaf está na capacidade do programa em estabilizar e manter o nível de emprego (SCHNEIDER e AQUINO, 2010; CLAESSENS e PEROTTI, 2004), de tal forma que, para cada operação de crédito efetuada através do Pronaf, são sustentadas 4,84 ocupações de trabalho e criada outra 0,58 (SCHNEIDER e AQUINO, 2010).

Do ponto de vista regional, outros trabalhos reforçam o efeito positivo do Pronaf na agricultura familiar: i) no Vale do Jequitinhonha (MG), o Pronaf tem promovido o desenvolvimento da economia local, o que levaria, indiretamente, à redução da pobreza (SILVA e ALVES, 2009); ii) na Zona Sul da Mata em Minas Gerais, o Pronaf aumentou a produção em $41,2 \%$ das unidades entrevistadas, além de elevar a renda e a produtividade em $20,6 \%$ e $14,7 \%$, respectivamente (RICCI, 1997); iii) na região do agreste de Pernambuco, o acesso ao crédito do Pronaf permitiu a elevação na área plantada para $80 \%$ dos agricultores familiares entrevistados. Além disto, permitiu aumentar o número de pessoas empregadas no empreendimento, tanto de familiares quanto terceiros.

Numa perspectiva mais ampla da economia regional e local, Mattei et al. (2007), também constatam o efeito positivo do Pronaf sobre a agricultura familiar. Os autores observaram que, na região Nordeste, maiores volumes de crédito do Pronaf estão associados a elevações na produção, na área colhida e no rendimento. Além disto, os recursos do programa passaram a apresentar maior grau de associação linear com as variáveis de natureza social, indicando que maiores volumes de recursos do programa tendem a melhorar os indicadores de desenvolvimento humano. Os resultados da análise de correlação para a região Sudeste e Norte são semelhantes aos da região Nordeste, ou seja: a existência de correlações fracas com destaque para a dimensão produtiva. Além disto, no período de 2000 a 2004, o acesso ao Pronaf fez com que 69\% de uma amostra de 100 municípios tivessem seu PIB agropecuário alterado positivamente, além da evidência da elevação na arrecadação de tributos em 56 deles, ainda em virtude do acesso ao crédito.

Portanto, os resultados e conclusões da literatura não são consensuais quanto aos efeitos socioeconômicos do Pronaf no rural brasileiro. Entretanto, um número maior de trabalhos tem apresentado conclusões teóricas e empíricas que relacionam o crédito do Pronaf com a elevação da produtividade e do dinamismo econômico e com a redução da pobreza e desigualdade.

\section{Metodologia}

Visando identificar os determinantes da variação da pobreza rural no Brasil, a abordagem econométrica deste trabalho estima duas elasticidades (renda domiciliar per capita-Pronaf e desigualdade de renda-Pronaf) a partir do montante de recursos monetários efetivamente concedidos pelo Pronaf aos Grupos A, B e A/C, que correspondem aos grupos de agricultores familiares de menor renda. Desta forma, o objetivo do trabalho consiste em identificar como os gastos com 
o Pronaf atuam sobre a renda e a desigualdade de renda no rural brasileiro. As bases de dados utilizadas são as do Pronaf, disponibilizadas pelo Banco Central do Brasil (Bacen) e os microdados da Pesquisa Nacional por Amostra de Domicílios (PNAD) do Instituto Brasileiro de Geografia e Estatística (IBGE). O modelo desenvolvido permite analisar os efeitos supostamente separados das variáveis explicativas, visando identificar a importância relativa de cada uma delas no período considerado (2001-2009) nas 27 Unidades Federativas sobre a variação da pobreza rural. Cabe ressaltar que, para as estimativas, considerando-se a situação censitária dos microdados da PNAD, foram selecionados apenas os domicílios e pessoas residentes no rural ${ }^{3}$.

\subsection{Dados e variáveis}

Neste trabalho, com exceção dos recursos do Pronaf, as demais variáveis (indicadores de pobreza, renda per capita e o Índice de GINI) foram obtidas a partir dos microdados da PNAD-IBGE e calculadas por meio do software Statistics/Data Analysis (STATA). Além disto, as variáveis renda per capita, pobreza e Pronaf estão em valores reais de 2009, deflacionadas pelo Índice Nacional de Preço ao Consumidor (INPC), também do IBGE, referente a setembro/2009, que é a data de referência de coleta das informações da PNAD.

Estabelecer a linha de pobreza consiste basicamente em determinar um critério binário que divide os indivíduos entre pobres e não pobres. O índice de pobreza utilizado é o de Foster, Greer e Thorbecke (1984), sendo que neste trabalho a pobreza é analisada, considerando-se uma abordagem unidimensional, sendo a renda o único critério que diferencia pobres e não pobres. A linha de pobreza adotada é de $1 / 2$ salário mínimo de 2009, deflacionada para os outros respectivos anos e, consequentemente, todo o estrato de indivíduos cuja renda per capita for inferior a esta linha é considerado pobre.

3. A definição de rural segue a classificação e metodologia da PNAD-IBGE.
Serão analisados três índices de pobreza: a proporção de pobreza $\left(\mathrm{P}_{0}\right)$, que indica a proporção de pessoas abaixo da linha de pobreza; o hiato da pobreza $\left(\mathrm{P}_{1}\right)$ que corresponde ao valor médio da distância da renda per capita dos pobres em relação à linha de pobreza e o quadrado do hiato da pobreza $\left(\mathrm{P}_{2}\right)$, que mensura a severidade da pobreza. Estes três índices podem ser representados, respectivamente pelas Equações 1, 2 e 3.

$$
\begin{aligned}
& P_{0}=\frac{q}{n} \\
& P_{1}=\frac{1}{n} \sum_{i=1}^{q}\left(\frac{z-y_{i}}{z}\right) \\
& P_{2}=\frac{1}{n} \sum_{i=1}^{q}\left(\frac{z-y_{i}}{z}\right)^{2}
\end{aligned}
$$

Em que: n é o número de pessoas na população, q, o número de pessoas pobres na população; $y_{\mathrm{i}}$ é o rendimento per capita do indivíduo i; z é a linha de pobreza.

O rendimento per capita do indivíduo $\mathrm{i}\left(\mathrm{y}_{\mathrm{i}}\right)$ foi calculado por meio da divisão do somatório dos rendimentos de todos os indivíduos de cada domicílio dividido pelo número de indivíduos.

$\mathrm{O}$ Índice de Gini corresponde à medida de desigualdade selecionada para expressar a desigualdade de renda rural, que pode ser expresso pela Equação 4. Este índice, que varia de 0 a 1, permite comparar a distribuição da renda com uma distribuição uniforme de igualdade de renda, sendo que, quanto mais próximo de 1 , mais desigual é a economia.

$$
\text { GINI }=\frac{1}{2 n^{2} \bar{y}} \sum_{i=1}^{n} \sum_{j=1}^{n}\left|y_{i}-y_{j}\right| ; i \neq j
$$

Em que: $\mathrm{n}$ é o total de indivíduos da amostra; $\mathrm{y}_{\mathrm{i}}$ é a renda per capita do indivíduo i; $\mathrm{y}=(1 / \mathrm{n}) \sum \mathrm{y}_{\mathrm{i}}$ representa a média aritmética da renda e $\left|y_{i}-y_{j}\right|$ representa a soma do valor absoluto de todas as distâncias entre rendas para todos os pares possíveis de indivíduos ${ }^{4}$.

4. O cálculo deste índice (assim como os índices de pobreza correspondentes às expressões (1), (2) e (3)) realizado através dos microdados da PNAD também deve ser feito de forma ponderada, utilizando-se os pesos dos indivíduos na amostra. 
Quadro 1. Classificação dos grupos beneficiados pelo Pronaf

\begin{tabular}{|c|l|l|}
\hline Grupo & \multicolumn{1}{|c|}{ Enquadramento } & \multicolumn{1}{|c|}{ Finalidade } \\
\hline A & $\begin{array}{l}\text { Agricultores familiares assentados pelo Programa Nacional de Reforma } \\
\text { Agrária (PNRA), público-alvo do Programa Nacional de Crédito Fun- } \\
\text { diário (PNCF), beneficiários do Programa de Recuperação de Assenta- } \\
\text { mentos (PRA) e os reassentados em função da construção de barragens. }\end{array}$ & $\begin{array}{l}\text { Estruturação dos lotes e recuperação da estru- } \\
\text { tura produtiva dos lotes. }\end{array}$ \\
\hline A/C & $\begin{array}{l}\text { Produtores (as) egressos (as) do Grupo "A", do Programa Especial de } \\
\text { Crédito para a Reforma Agrária (Procera) ou do "A Complementar". }\end{array}$ & Custeio de atividades agropecuárias. \\
\hline B & $\begin{array}{l}\text { Agricultores familiares com renda bruta anual familiar de até R\$ 20 } \\
\text { mil. }\end{array}$ & $\begin{array}{l}\text { Financiamento das atividades agropecuárias e } \\
\text { não agropecuárias no estabelecimento rural ou } \\
\text { áreas comunitárias próximas. }\end{array}$ \\
\hline
\end{tabular}

Fonte: Sebrae (2011) e MDA (2012).

Nota: Ver Sebrae (2011) e MDA (2012) para os demais critérios para classificação dos grupos e suas especificidades.

Os valores da variável Pronaf são referentes ao montante efetivamente emprestado em cada ano para os agricultores familiares dos Grupos A, B e A/C. Tais valores foram desagregados por Unidade Federativa no período 2001-2009, de acordo com a base de dados do Pronaf disponibilizada pelo Banco Central do Brasil.

Para canalizar adequadamente os créditos aos devidos produtores rurais, o Pronaf segue uma classificação dos beneficiários, e os classificam em grupos, que leva em conta algumas das características do produtor, como a renda anual e o tamanho da propriedade. Para a finalidade deste trabalho, interessa-nos os grupos A, B e $\mathrm{A} / \mathrm{C}$, que são aqueles nos quais se enquadram os agricultores familiares de rendas menores, cujas características estão apresentadas no Quadro 1.

Além das variáveis mencionadas acima, visando captar a heterogeneidade da incidência do Pronaf grupos A, B e A/C sobre a renda e a desigualdade de renda, também serão geradas algumas variáveis de controle: o inverso do nível de desenvolvimento inicial, a interação do Pronaf com a renda inicial e a desigualdade de renda inicial. A especificação completa dos modelos estimados será apresentada na Seção 3.

Além das variáveis mencionadas acima, visando captar a heterogeneidade da incidência do Pronaf grupos A, B e A/C sobre a renda e a desigualdade de renda, também serão geradas algumas variáveis de controle: o inverso do nível de desenvolvimento inicial, a interação do Pronaf com a renda inicial e a desigualdade de renda inicial. A especificação completa dos modelos estimados será apresentada na seção 3 .

A Tabela 1 apresenta as estatísticas descritivas das variáveis analisadas.

Tabela 1. Estatística descritiva das variáveis de dados em painel

\begin{tabular}{lcccc}
\hline \multicolumn{1}{c}{ Variável } & Mínimo & Máximo & Média & Desvio Padrão \\
\hline poverty0 & 19.8457 & 90.3414 & 63.9489 & 0.2741 \\
poverty1 & 6.9663 & 60.7252 & 33.0803 & 0.4109 \\
poverty2 & 3.8811 & 46.5113 & 21.3679 & 0.4939 \\
Renda per capita & 109.99 & 617.60 & 270.61 & 0.4251 \\
Coeficiente de GINI & 0.3613 & 0.6408 & 0.4752 & 0.0979 \\
Pronaf* & 1.5814 & 20908.641 & 3819.4110 & 1.0468 \\
$\mathrm{Z}_{\mathrm{it}} / \mathrm{Y}_{\mathrm{i} 0}{ }^{* *}$ & 0.2746 & 1.9717 & 0.9844 & 0.4239 \\
{$\left[\right.$ Pronaf $\left._{\mathrm{it}}\right] \cdot\left[\mathrm{Y}_{\mathrm{i} 0}\right]^{*}$} & 774.6266 & 4062000 & 728600 & 1.0708 \\
{$\left[\right.$ Pronaf $\left._{\mathrm{it}}\right] \cdot\left[\mathrm{G}_{\mathrm{i} 0}\right]^{* * *}$} & 0.9373 & 12001.560 & 1892.1850 & 1.0894 \\
\hline
\end{tabular}

* Em R $10.000,00 ;{ }^{* *} \mathrm{Z}_{\mathrm{it}}$ é o valor da linha de pobreza para a Unidade da Federação i e no ano t, $\mathrm{Y}_{\mathrm{i} 0}$ é a renda per capita na Unidade da Federação i no tempo $\mathrm{t}=0 ;{ }^{* * *} \mathrm{G}_{\mathrm{i} 0}$ é o Índice de Gini da Unidade da Federação i no tempo $\mathrm{t}=0$.

Fonte: Elaboração própria a partir dos microdados da PNAD/IBGE (2001-2009) e da base de dados do Pronaf - Bacen (2012). 
Como pode ser observado, há expressiva distância entre os valores máximos e mínimos de cada variável, o que se deve, sobretudo, a dois fatores: ao período temporal analisado, 2001-2009, no qual houve considerável redução da pobreza, elevação na renda e redução da desigualdade e, também, à heterogeneidade socioeconômica existente entre as Unidades Federativas. No caso particular do Pronaf, destacamos a heterogeneidade da incidência entre os grupos e regiões (mencionada no tópico 2.2.), além da existência de famílias que demandam elevados valores do Pronaf em detrimento de outras que demandam valores menores.

\subsection{Dados em painel}

Estimativas com modelos de dados em painel permitem avaliar mais consistentemente $\mathrm{e}^{5} \mathrm{o}$ efeito de uma variável sobre a outra, sendo particularmente no caso em estudo, o efeito do crédito do Pronaf sobre a renda domiciliar per capita e sobre a desigualdade de renda. A descrição geral do modelo é feita a seguir, seguindo a apresentação e notação de Baum (2006), sendo que o subscrito i representa a unidade de observação e o subscrito $t$, o período de tempo correspondente, de tal forma que com $\mathrm{T}$ observações temporais para cada um dos $\mathrm{N}$ indivíduos, o modelo passa a conter, em sua forma mais original e simples, $\mathrm{k} \times \mathrm{N}$ $x \mathrm{~T}$ coeficientes de regressão ${ }^{6}$, podendo ser ilustrado como:

$$
y_{i t}=\sum_{k=1}^{K} x_{k i t} \beta_{k i t}+\varepsilon_{i t}, \quad i=1, \ldots, N, \quad i=1, \ldots, T
$$

Em que: $\mathrm{N}$ é o número de indivíduos (Unidades Federativas); T é o número de perío-

5. Quando comparadas a estimativas obtidas a partir de modelos com dados cross-section.

6. A forma geral da expressão (5) impossibilita a estimação pelos métodos econométricos usuais. Por exemplo, pelo método dos momentos, teríamos $\mathrm{N}$ equações de momento e k x N x T parâmetros a serem estimados. Desta forma, para a estimativa de modelos de dados em painel temos que restringir o número de parâmetros - uma das medidas é a suposição de invariância dos parâmetros tanto para indivíduos como para unidades temporais. Nas expressões (6) e (7), a seguir, é introduzida esta restrição e o termo de efeito individual fixo no tempo. dos (ano); $\varepsilon_{\mathrm{it}}$ é o termo de erro; $\beta_{\mathrm{kit}}$ representa os valores dos parâmetros a serem estimados e $\mathrm{x}_{\text {kiy }}$ representa os valores observados das variáveis independentes selecionadas para análise. Este modelo é muito geral e o número de observações é menor do que o número de parâmetros a serem estimados, sendo necessária uma simplificação, supondo parâmetros constantes no tempo e para as observações.

Dado o objetivo do trabalho, inicialmente são especificados os seguintes modelos para dados em painel:

$$
\begin{aligned}
& \ln \left[Y_{i t}\right]=\beta_{0}+\beta_{1} \ln \left[\text { Pronaf }_{i t}\right]+\eta_{i}+\mu_{i t} \\
& \Delta \ln \left[\text { Gini i }_{i t}\right]=\beta_{0}+\beta_{1} \ln \left[\text { Pronaf }_{i t}\right]+\eta_{i}+\mu_{i t}
\end{aligned}
$$

Em que $Y_{i t}$ é a renda domiciliar per capita, Gini $_{i t}$ é o Índice de Gini, o termo $\eta_{i}$ capta os efeitos individuais não observáveis (supostamente fixos no tempo) dos indivíduos, e $\mu_{\mathrm{it}}$ são os distúrbios aleatórios idiossincráticos.

Nas equações 6 e 7 são acrescentados, respectivamente, nas variáveis explicativas, os termos: $\mathrm{Y}_{\mathrm{it}-1}$ que é a renda per capita defasada de um período e Gini $i_{\mathrm{it}-1}$ que é o Índice de Gini defasado de um período. A inclusão da variável dependente defasada em um período levanta a hipótese de que variações nas variáveis independentes no período $\mathrm{t}$ tendem a influenciar sua dinâmica no período $t+1$. Para Baltagi (2001), esta adaptação permite entender melhor os ajustamentos das relações econômicas dinâmicas no modelo. A representação algébrica passa a ser definida como:

$$
\begin{aligned}
& \ln \left[Y_{\mathrm{it}}\right]=\beta_{0}+\beta_{1} \ln \left[Y_{\mathrm{it}-1}\right]+\beta_{2} \ln \left[\text { Pronaf }_{\mathrm{it}}\right]+\eta_{\mathrm{i}}+\mu_{\mathrm{it}} \\
& \ln \left[\text { Gini }_{\mathrm{it}}\right]=\beta_{0}+\beta_{1} \ln \left[\text { Gini i }_{\mathrm{it}-1}\right]+\beta_{2} \ln \left[\text { Pronaf }_{\mathrm{it}}\right]+\eta_{\mathrm{i}}+\mu_{\mathrm{it}}
\end{aligned}
$$

Entretanto, a introdução das variáveis defasadas $\mathrm{Y}_{\mathrm{it}-1}$ entre as variáveis explicativas nas equações 8 e 9 torna as estimativas por Mínimos Quadrados Ordinários (MQO) inconsistentes e viesadas, dado que $\mathrm{Y}_{\mathrm{it}-1}$ (assim como Gini $\mathrm{it}_{\mathrm{it}-1}$ ) é uma função de $\mu_{\text {it }}$ (e portanto, correlacionados com este termo). Este problema pode ser resolvido ao transformar a equação 8 , por exemplo, em primeira diferença, adotando $\Delta \ln \left[\mathrm{Y}_{\mathrm{it}-2}\right]$ e os 
demais lags como instrumentos para $\Delta \ln \left[\mathrm{Y}_{\mathrm{it}-1}\right]$ (ANDERSON e HSIAO, 1981). Com este procedimento, os instrumentos em nível fazem com que o estimador deixe de conter singularidades, o que não ocorre quando é utilizada a segunda defasagem da variável dependente em diferença. Desta forma, a variância é reduzida, os efeitos individuais são eliminados e as inconsistências do modelo são removidas. A partir destas considerações, chegamos à equação 10 , definida em termos do logaritmo natural, em que $\Delta$ é o operador de diferença. O mesmo procedimento é adotado para a equação 9, gerando, consequentemente, a equação 11.

$\Delta \ln \left[Y_{\mathrm{it}}\right]=\beta_{0}+\beta_{1} \Delta \ln \left[\mathrm{Y}_{\mathrm{it}-1}\right]+\beta_{2} \Delta \ln \left[\right.$ Pronaf $\left._{\mathrm{it}}\right]+\Delta \mu_{\mathrm{it}}$

$\Delta \ln \left[\mathrm{Gini}_{\mathrm{it}}\right]=\beta_{0}+\beta_{1} \Delta \ln \left[\mathrm{Gini}_{\mathrm{it}-1}\right]+\beta_{2} \Delta \ln \left[\operatorname{Pronaf}_{\mathrm{it}}\right]+\Delta \mu_{\mathrm{it}}$

Nas equações 10 e 11, $\Delta \ln \left[Y_{i t}\right]=\ln Y_{i t}-\ln Y_{i t-1}$ é a variação do logaritmo natural da renda domiciliar per capita entre o período t e $t-1$; da mesma forma, $\Delta \ln \left[\mathrm{Gini}_{\mathrm{it}}\right]=\ln \mathrm{Gini}_{\mathrm{it}}-\ln \mathrm{Gini}_{\mathrm{it}-1}$ é a variação do logaritmo natural da concentração de renda mensurada pelo Índice de Gini entre o período t e t-1. A variável explicativa $\Delta \ln \left[\right.$ Pronaf $_{\mathrm{it}}$ ] também expressa a variação do seu logaritmo natural entre o período $t$ e $t$ - 1 , em que os coeficientes $\beta_{2}$ em ambas as equações representam, respectivamente, as elasticidades renda domiciliar per capita-Pronaf e desigualdade de renda-Pronaf.

Como apresentado por Baltagi (2005), a estimação das elasticidades tende a gerar resultados mais eficientes, em relação a Anderson e Hsiao (1981), a partir do esforço em estabelecer uma estimação em dois estágios para construir condições de momento a partir dos níveis defasados da variável dependente, como foi proposto por Arellano e Bond (1991). Neste caso, acrescentam-se mais equações de momento correspondentes aos níveis defasados de $\mathrm{Y}_{\text {it }}$ (a partir de $\ln \mathrm{Y}_{\mathrm{it}-2}$ ), que teoricamente são não correlacionados com a primeira diferença dos erros idiossincráticos; da mesma forma para Gini $i_{\text {it }}$ (a partir de ln Gini $i_{\text {it-2 }}$ ), que também são instrumentos teoricamente válidos em relação à primeira diferença dos erros idiossincráticos (BALTAGI, 2005).
Por outro lado, o estimador proposto por Arellano e Bond (1991) apresenta problemas, como destacado por Arellano-Bover (1995) e Blundell-Bond (1998) por meio de simulações (BALTAGI, 2005). O Estimador ArellanoBover (1995)/Blundell-Bond (1998) (Método dos Momentos Generalizado para Sistema - GMMsistema) baseia-se em um sistema de equações. A equação diferenciada é instrumentalizada pelas defasagens dos níveis das variáveis como proposto em Arellano e Bond (1991) e a equação em nível é instrumentalizada pelas defasagens das diferenças. Deve-se, entretanto, admitir o pressuposto de que a primeira diferença das variáveis explicativas não seja correlacionada com os efeitos fixos, os instrumentos utilizados sejam válidos e que os erros não tenham correlação serial de segunda ordem. A partir do método GMMsistema é possível a adoção de instrumentos adicionais e gerar mais precisão (mais eficiência) do estimador em relação ao estimador proposto em Arellano e Bond (1991).

Definida a modelagem econométrica, este trabalho parte do princípio de que o Pronaf atuaria sobre a pobreza rural indiretamente e por duas vias: pela elevação da renda e/ou através da redução da desigualdade de renda; ambos os efeitos reduziriam a cauda da curva de distribuição de renda à esquerda da linha de pobreza e, consequentemente, mitigariam a pobreza rural. O primeiro princípio relaciona o crédito oferecido pelo programa (Grupos A, B e A/C) com a elevação da renda dos agricultores de menor renda, o que, consequentemente, aumentaria os rendimentos no meio rural e deslocaria a curva de distribuição de rendimentos à direita. $\mathrm{O}$ segundo princípio é o redistributivo, ou seja, o acesso ao crédito (Grupos A, B e A/C) ao elevar a renda dos produtores rurais, coeterisparibus, permitiria a redução da desigualdade de renda, através de uma mudança na forma da distribuição dos rendimentos de forma que a área da cauda à esquerda da linha de pobreza se reduza.

Entretanto, cabe destacar que o efeito geral do Pronaf, levando em conta todas as modalidades de crédito, pode resultar numa possível 
concentração de renda. Se observada esta concentração, não estimada neste trabalho, o efeito poderia ser explicado tendo em vista que a maior parte dos recursos do Pronaf é destinada aos produtores rurais mais capitalizados, ou seja, aqueles que não fazem parte dos grupos A, B e $\mathrm{A} / \mathrm{C}$; cabe ressaltar, ainda, o efeito não observado das outras modalidades de crédito rural, além do Pronaf, que correspondem a uma fatia considerável do total do crédito rural (IPEA, 2013; IBGE, 2009).

Visando identificar a validade dos instrumentos utilizados para a estimação em GMM-sistema, será apresentado, junto aos resultados, o Teste Hansen e os Testes Arellano-Bond de autocorrelação de primeira e segunda ordem dos resíduos. Por fim, para o estimador within groups, o valor do Teste Hausman, a partir do confronto entre o modelo de efeitos fixos com o modelo aleatório, tende a apresentar qual deles é mais indicado e, portanto, indicando qual modelo constará nos resultados.

Levando-se em conta as especificidades socioeconômicas entre as Unidades Federativas brasileiras, é de se pressupor que o crédito do Pronaf apresente efeitos heterogêneos nas diferentes Unidades Federativas do País. Com base nas abordagens de Kalwij e Verschoor (2004 apud ARAÚJO e MARINHO, 2012) e Batista (2014), a criação de variáveis de interação permitiria captar parte desta heterogeneidade. Ajustando aos objetivos do trabalho, a análise de sinal leva a conclusões que relacionam à maior, ou menor, capacidade dos créditos repassados pelo Pronaf (Grupos A, B e A/C) em alterar a renda per capita e a desigualdade de renda rural e, consequentemente, seu efeito indireto sobre a pobreza rural.

Tendo isto em vista, são geradas variáveis de interação e duas novas estimativas (Dados em Painel GMM-sistema), a fim de estabelecer a análise de sinal dos coeficientes estimados, como é representado nas Equações 12 e 13.

$$
\begin{aligned}
& \Delta \ln \left[\mathrm{Y}_{\mathrm{it}}\right]=\beta_{0}+\beta_{1} \Delta \ln \left[\mathrm{Y}_{\mathrm{it}-1}\right]+\beta_{2} \Delta \ln \left[\text { Pronaf }_{\mathrm{it}}\right]+ \\
& \beta_{3} \Delta \ln \left[\mathrm{Z}_{\mathrm{it}} / Y_{\mathrm{i} 0}\right]+\beta_{4} \Delta \ln \left[\operatorname{Pronaf} \mathrm{f}_{\mathrm{it}}\right] \cdot\left[\mathrm{Y}_{\mathrm{i} 0}\right]+ \\
& \beta_{5} \Delta \ln \left[\operatorname{Pronaf}_{\mathrm{it}}\right] \cdot\left[\mathrm{Z}_{\mathrm{it}} / \mathrm{Y}_{\mathrm{i} 0}\right]+\beta_{6} 1 \cdot \text { ano }+\Delta \mu_{\mathrm{it}}
\end{aligned}
$$

$$
\begin{aligned}
& \Delta \ln \left[\text { Gini }_{\mathrm{it}}\right]=\beta_{0}+\beta_{1} \Delta \ln \left[\text { Gini }_{\mathrm{it}-1}\right]+ \\
& \beta_{2} \Delta \ln \left[\operatorname{Pronaf}_{\mathrm{it}}\right]+\beta_{3} \Delta \ln \left[\mathrm{Z}_{\mathrm{it}} / \mathrm{Y}_{\mathrm{i} 0}\right]+ \\
& \beta_{4} \Delta \ln \left[\text { Pronaf }_{\mathrm{it}}\right] \cdot\left[\mathrm{G}_{\mathrm{i} 0}\right]+ \\
& \beta_{5} \Delta \ln \left[\operatorname{Pronaf}_{\mathrm{it}}\right] .\left[\mathrm{Z}_{\mathrm{it}} / Y_{\mathrm{i} 0}\right]+\beta_{6} 1 . \text { ano }+\Delta \mu_{\mathrm{it}}
\end{aligned}
$$

Em que $z_{\text {it }}$ é a linha de pobreza na Unidade Federativa i e no tempo t; $Y_{i 0}$ e $G_{i 0}$ são a renda per capita e a desigualdade de renda, respectivamente, da Unidade Federativa i no tempo $\mathrm{t}=0$. Assim como definido anteriormente, ' $\Delta \mathrm{ln}^{\prime}$ representa a variação do logaritmo das variáveis explicativas entre o período $t \mathrm{e} t+1$. Desta forma, a variável $\mathrm{z}_{\mathrm{i} i} / Y_{\mathrm{i} 0}$ é o inverso do nível inicial de desenvolvimento. [Pronaf $\left.\mathrm{f}_{\mathrm{it}}\right]$. $\left[\mathrm{Y}_{\mathrm{i} 0}\right]$ é a variável de interação entre o crédito concedido pelo Pronaf (Grupos A, B e A/C) e a renda inicial per capita média da unidade de observação. [Pronaf $\left.{ }_{\mathrm{it}}\right]$. $\left[\mathrm{G}_{\mathrm{i} 0}\right]$ é a variável de interação entre o crédito concedido pelo Pronaf (Grupos A, B e A/C) e a desigualdade de renda inicial. Por fim, $\left[\right.$ Pronaf $\left._{i t}\right]$. $\left[\mathrm{z}_{\mathrm{i} 0} / Y_{\mathrm{i} 0}\right]$ é a variável de interação entre o crédito do Pronaf e o nível inicial de desenvolvimento. Além das variáveis de interação, também é incluída no modelo uma variável de tendência ano.

Entretanto, antes de apresentar os resultados do objetivo principal deste trabalho (a relação indireta da variável Pronaf para com a variação da pobreza rural), cabe apresentar os resultados que corroboram o pressuposto de Borguignon (2002) para o meio rural brasileiro. Ou seja, consiste em apresentar a relação entre a variável pobreza com a desigualdade de renda e a renda domiciliar per capita.

Para isto, também serão realizadas estimativas em GMM-sistema, cuja construção metodológica respeita o modelo desenvolvido acima, resultando na equação 14:

$\Delta \ln \left[\mathrm{P}_{\mathrm{k}, \mathrm{it}}\right]=\beta_{0}+\beta_{1} \Delta \ln \left[\mathrm{Y}_{\mathrm{it}}\right]+\beta_{2} \Delta \ln \left[\mathrm{Ginin}_{\mathrm{it}}\right]+\Delta \mu_{\mathrm{it}}$

em que $\Delta \ln \left[\mathrm{P}_{\mathrm{k}, \mathrm{i}}\right]=\ln \mathrm{P}_{\mathrm{k}, \mathrm{i}}-\ln \mathrm{P}_{\mathrm{k}, \mathrm{it}-1}$ é a variação do logaritmo natural da pobreza de acordo com o parâmetro $\mathrm{k}(\mathrm{k}=0$ para a proporção da pobreza; $\mathrm{k}=1$ para o hiato da pobreza e $\mathrm{k}=2$ para o quadrado do hiato da pobreza) entre o períodotet-1; $\Delta \ln \left[Y_{\mathrm{it}}\right]=\ln Y_{\mathrm{it}}-\ln Y_{\mathrm{it}-1}$ e $\Delta \ln \left[\right.$ Gini it $\left._{i t}\right]=\ln$ Gini $_{i t}-\ln$ Gini $_{\mathrm{it}-1}$ já foram definidos anteriormente. 


\section{Análise dos resultados}

A pobreza rural no Brasil guarda suas especificidades de tal forma que um conjunto de outros elementos (além das variáveis analisadas neste trabalho) também tem papel importante em explicar a sua variação, dentre eles, o mercado de trabalho, a valorização do salário mínimo, a previdência pública e os programas de transferência de renda (GAIGER, 2011).

Além do uso do estimador GMM-sistema, também foram realizadas, para fins de comparação, as mesmas estimativas utilizando os estimadores de Mínimos Quadrados Ordinários (MQO) e de within groups ${ }^{7}$, utilizando a mesma especificação do modelo, incluindo a variável dependente defasada. Serão descritos, entretanto, apenas os resultados do estimador GMM-sistema; os outros estimadores mencionados acima têm como finalidade indicar se os valores estimados da variável defasada em GMM-sistema se situam entre os coeficientes estimados desta mesma variável em MQO e within groups. Caso situe entre os dentro deste intervalo de coeficientes, as estimações a partir de GMM-sistema possibilitam a redução do viés de estimação, uma vez que, para a construção do modelo, foi incluída a variável dependente defasada de um período, bem como a presença dos efeitos fixos não observáveis entre as variáveis explicativas.

Nas tabelas dos resultados, os valores entre parênteses são os erros padrões robustos, Arellano e Bond (Arellano e Bond ( $\operatorname{ar} 1 p)$ ) corresponde ao teste de autocorrelação de Arellano-Bond para correlação de primeira ordem para as diferenças dos erros do modelo; da mesma forma, Arellano e Bond (Arellano e Bond (ar2p)) é o teste de autocorrelação de Arellano-Bond para correlação de segunda ordem para as diferenças dos erros do modelo.

7. O Teste Hausman, para confronto entre modelos de efeitos aleatórios e de efeitos fixos, apontou, para todas as estimativas, o Modelo de Efeitos Fixos como o mais indicado. Neste modelo, os coeficientes estimados são robustos e na forma log-log.
Os valores dos testes Arellano e Bond (ar1p), Arellano e Bond ( $a r 2 p)$ e do Teste Hansen (de restrição de sobreidentificação) se referem a p-valores correspondentes às estatísticas de teste. Nas estimativas, também foi utilizada a opção collapse do comando xtabond 2 do STATA, para reduzir a quantidade de instrumentos, evitando situações de proliferação de instrumentos, o que poderia enfraquecer os testes.

Feita tais considerações, a Tabela 2 apresenta a variação da pobreza rural resultante da variação da renda domiciliar per capita rural e da desigualdade de renda rural. Os valores e sinais das estimativas estão de acordo com as referências bibliográficas (HELFAND e ROCHA, 2008; BORGUIGNON, 2002; CASTELAR, TABOSA e IRFFI, 2013; KAKWANI e PERNI, 2000; ADAMS, 2002; ZAULI, 2005; HOFFMANN, 2006), segundo a qual acréscimos na renda e decréscimos na concentração de renda tendem a reduzir a pobreza.

Para os K parâmetros ( $\mathrm{k}=0$ para a proporção da pobreza; $\mathrm{k}=1$ para o hiato da pobreza e $\mathrm{k}=2$ para o quadrado do hiato da pobreza), o módulo das elasticidades da desigualdade da pobreza são maiores que os módulos das elasticidades renda da pobreza, o que indica que políticas voltadas para a promoção da igualdade são mais eficientes que as voltadas para a elevação da renda das famílias rurais visando à mitigação da pobreza. Além disto, o valor, em módulo, das elasticidades, é maior para o quadrado do hiato da pobreza, ou seja, este parâmetro da pobreza é mais sensível a estas duas variáveis.

A estimação em GMM-sistema permitiu reduzir o viés de estimação do modelo, dada a inclusão da variável dependente defasada em um período entre as variáveis explicativas do modelo. Esta conclusão é constatada pela significância estatística da estimação em GMM-sistema e o valor desta variável, que se situam entre os coeficientes estimados desta mesma variável em MQO e within group ${ }^{8}$. Ou seja, há persistência da

8. As estimativas complementares não constam deste trabalho. Além da constatação da posição da variável dependente defasada em GMM-sistema, cabe ressaltar que as demais estimativas apresentaram significância estatística 
Tabela 2. Elasticidade-renda per capita da pobreza e desigualdade da pobreza para $\Delta \ln \left[\mathrm{P}_{\mathrm{k}, \mathrm{it}}\right]$

\begin{tabular}{|c|c|c|c|c|c|c|}
\hline & \multicolumn{2}{|c|}{$\mathbf{P}_{0}$} & \multicolumn{2}{|c|}{$\mathbf{P}_{1}$} & \multicolumn{2}{|c|}{$\mathbf{P}_{2}$} \\
\hline & Coefic. & Valor- $p$ & Coefic. & Valor-p & Coefic. & Valor-p \\
\hline $\ln \left[\mathrm{P}_{\mathrm{K}, \mathrm{it}-1}\right]$ & $\begin{array}{c}0.5012 \\
(0.1312) \\
\end{array}$ & 0.001 & $\begin{array}{c}0.2729 \\
(0.1049) \\
\end{array}$ & 0.015 & $\begin{array}{c}0.1526 \\
(0.0634) \\
\end{array}$ & 0.023 \\
\hline $\ln \left[Y_{i t-1}\right]$ & $\begin{array}{c}-0.3466 \\
(0.0958) \\
\end{array}$ & 0.001 & $\begin{array}{c}-0.75645 \\
(0.13136) \\
\end{array}$ & 0.000 & $\begin{array}{l}-1.0306 \\
(0.1088) \\
\end{array}$ & 0.000 \\
\hline $\ln \left[\mathrm{Gini}_{\mathrm{it}}\right]$ & $\begin{array}{c}0.8348 \\
(0.2905) \\
\end{array}$ & 0.008 & $\begin{array}{l}1.42858 \\
(0.2694) \\
\end{array}$ & 0.000 & $\begin{array}{c}1.9433 \\
(0.2589) \\
\end{array}$ & 0.000 \\
\hline \multirow[t]{3}{*}{ Constante } & $\begin{array}{c}4.5688 \\
(1.2204) \\
\end{array}$ & 0.001 & $\begin{array}{c}7.7021 \\
(0.2266) \\
\end{array}$ & 0.000 & $\begin{array}{c}9.6036 \\
(0.8647) \\
\end{array}$ & 0.000 \\
\hline & \multicolumn{2}{|c|}{$F(3,26)=209.14$} & \multicolumn{2}{|c|}{$F(3,26)=375.39$} & \multicolumn{2}{|c|}{$F(3,26)=425.43$} \\
\hline & \multicolumn{2}{|c|}{ Prob $>F=0.000$} & \multicolumn{2}{|c|}{ Prob $>F=0.000$} & \multicolumn{2}{|c|}{ Prob $>F=0.000$} \\
\hline $\mathrm{N}^{\circ}$ de observações & \multicolumn{2}{|c|}{195} & \multicolumn{2}{|c|}{195} & & \\
\hline $\mathrm{N}^{\circ}$ de grupos & \multicolumn{2}{|c|}{27} & \multicolumn{2}{|c|}{27} & \multicolumn{2}{|c|}{27} \\
\hline $\mathrm{N}^{\circ}$ de instrumento & \multicolumn{2}{|c|}{25} & \multicolumn{2}{|c|}{25} & \multicolumn{2}{|c|}{25} \\
\hline Arellano e Bond (ar1p) & \multicolumn{2}{|c|}{0.004} & \multicolumn{2}{|c|}{0.001} & \multicolumn{2}{|c|}{0.002} \\
\hline Arellano e Bond (ar2p) & \multicolumn{2}{|c|}{0.471} & \multicolumn{2}{|c|}{0.451} & \multicolumn{2}{|c|}{0.184} \\
\hline Teste Hansen & \multicolumn{2}{|c|}{0.280} & \multicolumn{2}{|c|}{0.461} & \multicolumn{2}{|c|}{0.465} \\
\hline
\end{tabular}

Fonte: Elaboração dos autores a partir dos microdados da PNAD/IBGE (2001-2009).

pobreza no tempo, o que indica que a pobreza no período $t$ tende a influenciar positivamente a pobreza no período $t+1$.

Quanto às elasticidades estimadas, uma variação positiva de $10 \%$ na renda tende a reduzir a proporção da pobreza em $3,46 \%$, o hiato da pobreza, em $7,56 \%$, e o quadrado do hiato da pobreza, em $10,30 \%$. Da mesma forma que a redução da desigualdade de renda em $10 \%$ tende a reduzir a proporção da pobreza em $8,35 \%$, o hiato da pobreza, em $14,29 \%$, e o quadrado do hiato da pobreza, em 19,43\%.

Constatando-se as relações entre renda-pobreza e desigualdade-pobreza, as Tabelas 3 e 4 apresentam os resultados das estimativas para as elasticidades renda per capita-Pronaf e desigualdade de renda-Pronaf. Nestas estimativas, pode ser observada a persistência da renda domiciliar per capita e do coeficiente de concentração de renda, $\ln \left[\mathrm{Y}_{\mathrm{it}-1}\right]$ e $\ln \left[\mathrm{Gini}_{\mathrm{it}-1}\right]$, respectivamente, dado que o valor desta estimativa situa-se entre as estimativas da mesma variável em MQO e Fixed-Effects, além de serem estatisticamente sig-

e com sinal condizente aos da Tabela 2. Além disto, o elevado valor da estatística $R 2$, superior a 0,9 para todos os casos, indica o alto poder explicativo das variáveis independentes selecionadas sobre a variável dependente. nificativas. Estes resultados permitem o levantamento de duas conclusões: a primeira é que as estimativas em GMM-sistema auxiliam na redução do viés de estimação, através da inclusão da variável dependente defasada em um período e da presença dos efeitos fixos não observáveis entre as variáveis explicativas; a segunda é que permite observar que a renda domiciliar per capita e a desigualdade de renda do presente tendem a influenciar estas mesmas variáveis no futuro, indicando uma persistência no tempo. Além disto, como seus valores foram menores que a unidade, pode-se observar que este efeito defasado não é explosivo.

As estimativas sugerem que uma elevação em 10\% do crédito do Pronaf (Grupos A, B e A/C) tende a elevar a renda per capita domiciliar rural em $0,24 \%$ e a reduzir a desigualdade de renda em $0,36 \%$. Estes valores apresentam, portanto, a incidência indireta da variável Pronaf na redução da pobreza em duas vias: pelo aumento da renda domiciliar per capita e pela melhor distribuição de renda mensurada pelo Índice de Gini.

São escassas na literatura econômica evidências empíricas que relacionam o Pronaf com a distribuição de renda; por outro lado, os resultados obtidos nesta seção para a relação renda per 
Tabela 3. Elasticidade-renda per capita - Pronaf

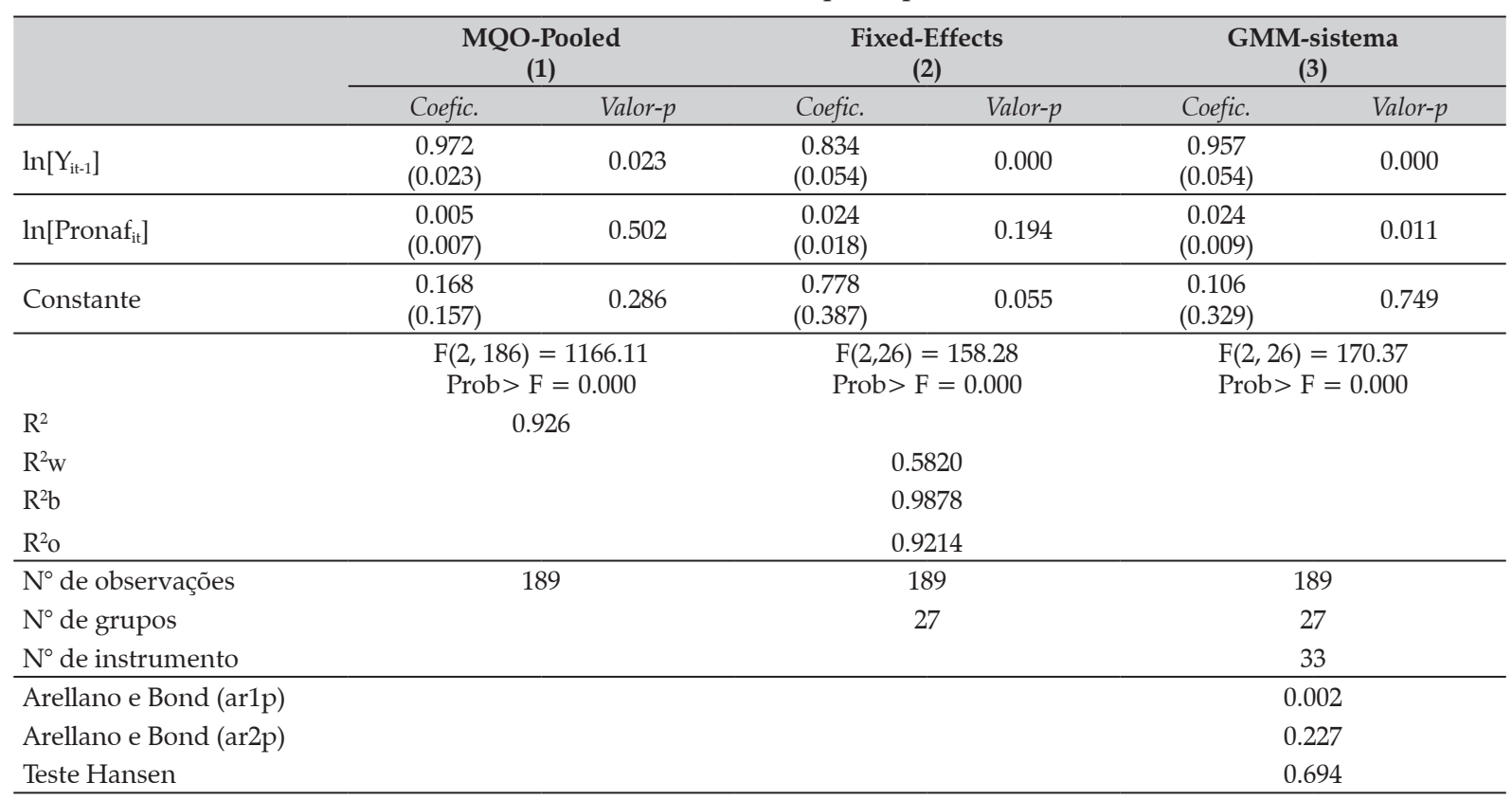

Fonte: Elaboração dos autores a partir dos microdados da PNAD/IBGE (2001-2009) e da base de dados do Pronaf - Bacen (2012).

Tabela 4. Elasticidade Desigualdade de renda - Pronaf

\begin{tabular}{|c|c|c|c|c|c|c|}
\hline & \multicolumn{2}{|c|}{$\begin{array}{l}\text { MQO-Pooled } \\
\text { (1) }\end{array}$} & \multicolumn{2}{|c|}{$\begin{array}{c}\text { Fixed-Effects } \\
\text { (2) }\end{array}$} & \multicolumn{2}{|c|}{$\begin{array}{c}\text { GMM-sistema } \\
\text { (3) }\end{array}$} \\
\hline & Coefic. & Valor-p & Coefic. & Valor- $p$ & Coefic. & Valor-p \\
\hline $\ln \left[\mathrm{Gini}_{\mathrm{it}-1}\right]$ & $\begin{array}{c}0.374 \\
(0.063)\end{array}$ & 0.000 & $\begin{array}{c}0.010 \\
(0.073) \\
\end{array}$ & 0.892 & $\begin{array}{c}0.046 \\
(0.102) \\
\end{array}$ & 0.658 \\
\hline $\ln \left[\right.$ Pronaf $\left._{\mathrm{it}}\right]$ & $\begin{array}{l}-0.003 \\
(0.004) \\
\end{array}$ & 0.500 & $\begin{array}{c}0.017 \\
(0.011) \\
\end{array}$ & 0.130 & $\begin{array}{l}-0.036 \\
(0.014) \\
\end{array}$ & 0.015 \\
\hline \multirow[t]{2}{*}{ Constante } & $\begin{array}{l}-0.461 \\
(0.053) \\
\end{array}$ & 0.000 & $\begin{array}{l}-0.885 \\
(0.081) \\
\end{array}$ & 0.000 & $\begin{array}{l}-0.447 \\
(0.119)\end{array}$ & 0.001 \\
\hline & \multicolumn{2}{|c|}{$\begin{array}{c}\mathrm{F}(2,186)= \\
\text { Prob }>\mathrm{F}=0.000\end{array}$} & \multicolumn{2}{|c|}{$\begin{array}{c}F(2,26)=1.33 \\
\text { Prob }>F=0.2828\end{array}$} & \multicolumn{2}{|c|}{$\begin{aligned} \mathrm{F}(2,26) & =3.76 \\
\text { Prob }>\mathrm{F} & =0.037\end{aligned}$} \\
\hline $\mathrm{R}^{2}$ & \multicolumn{2}{|c|}{0.1692} & & & & \\
\hline $\mathrm{R}^{2} \mathrm{w}$ & \multicolumn{6}{|c|}{0.0170} \\
\hline $\mathrm{R}^{2} \mathrm{~b}$ & \multicolumn{6}{|c|}{0.2071} \\
\hline $\mathrm{R}^{2} \mathrm{O}$ & \multicolumn{6}{|c|}{0.0084} \\
\hline $\mathrm{N}^{\circ}$ de observações & \multicolumn{2}{|c|}{189} & \multicolumn{2}{|c|}{189} & \multicolumn{2}{|c|}{189} \\
\hline $\mathrm{N}^{\circ}$ de grupos & & & \multicolumn{2}{|c|}{27} & \multicolumn{2}{|c|}{27} \\
\hline $\mathrm{N}^{\circ}$ de instrumento & & & & & \multicolumn{2}{|c|}{17} \\
\hline Arellano e Bond (ar1p) & & & & & \multicolumn{2}{|c|}{0.005} \\
\hline Arellano e Bond (ar2p) & & & & & \multicolumn{2}{|c|}{0.104} \\
\hline Teste Hansen & & & & & \multicolumn{2}{|c|}{0.090} \\
\hline
\end{tabular}

Fonte: Elaboração dos autores a partir dos microdados da PNAD/IBGE (2001-2009) e da base de dados do Pronaf - Bacen (2012). 
capita-Pronaf estão de acordo com parte da literatura analisada que associa o crédito do programa com o aumento da renda e da produtividade, dado que o aumento da produtividade tende a elevar a renda dos agricultores familiares (RICCI, 1997; FAVERO e ALVES, 2002; MATTEI, 2005; MATTEI et al., 2007).

Importante ressaltar, que as estatísticas $\mathrm{R}^{2}$ das estimativas em MQO-Pooled e Fixed-Effects para a Elasticidade-renda per capita-Pronaf (Tabela 3) apontam para a elevada capacidade das variáveis independentes em explicar a variação da renda domiciliar per capita média. Entretanto, para a Elasticidade Desigualdade de renda-Pronaf (Tabela 4), as estatísticas $\mathrm{R}^{2}$ apresentaram reduzida capacidade das variáveis independentes em explicar a variação da desigualdade de renda mensurada pelo Índice de Gini.
Complementarmente às análises, para os parâmetros das elasticidades das Tabelas 2, 3 e 4, os Testes Arellano e Bond indicam que podemos rejeitar a hipótese nula de ausência de autocorrelação de primeira ordem e aceitar a existência de autocorrelação de segunda ordem dos erros em nível. E os resultados para o Teste Hansen permitem aceitar as hipóteses de que os instrumentos utilizados na estimação dos modelos de elasticidade GMM-sistema são válidos ao nível de significância de $5 \%$.

A primeira constatação das estimativas, Tabelas 5 e 6, está no valor do coeficiente estimado em GMM-Sistema para $\Delta \ln \left[Y_{i t-1}\right]$ que, além de apresentar significância estatística, situa-se entre as estimativas da mesma variável em MQOPooled e Fixed-Effects. Logo, estimar em GMMSistema permite mitigar o problema de viés de

Tabela 5. Análise de sinal: Elasticidade Pronaf - Renda

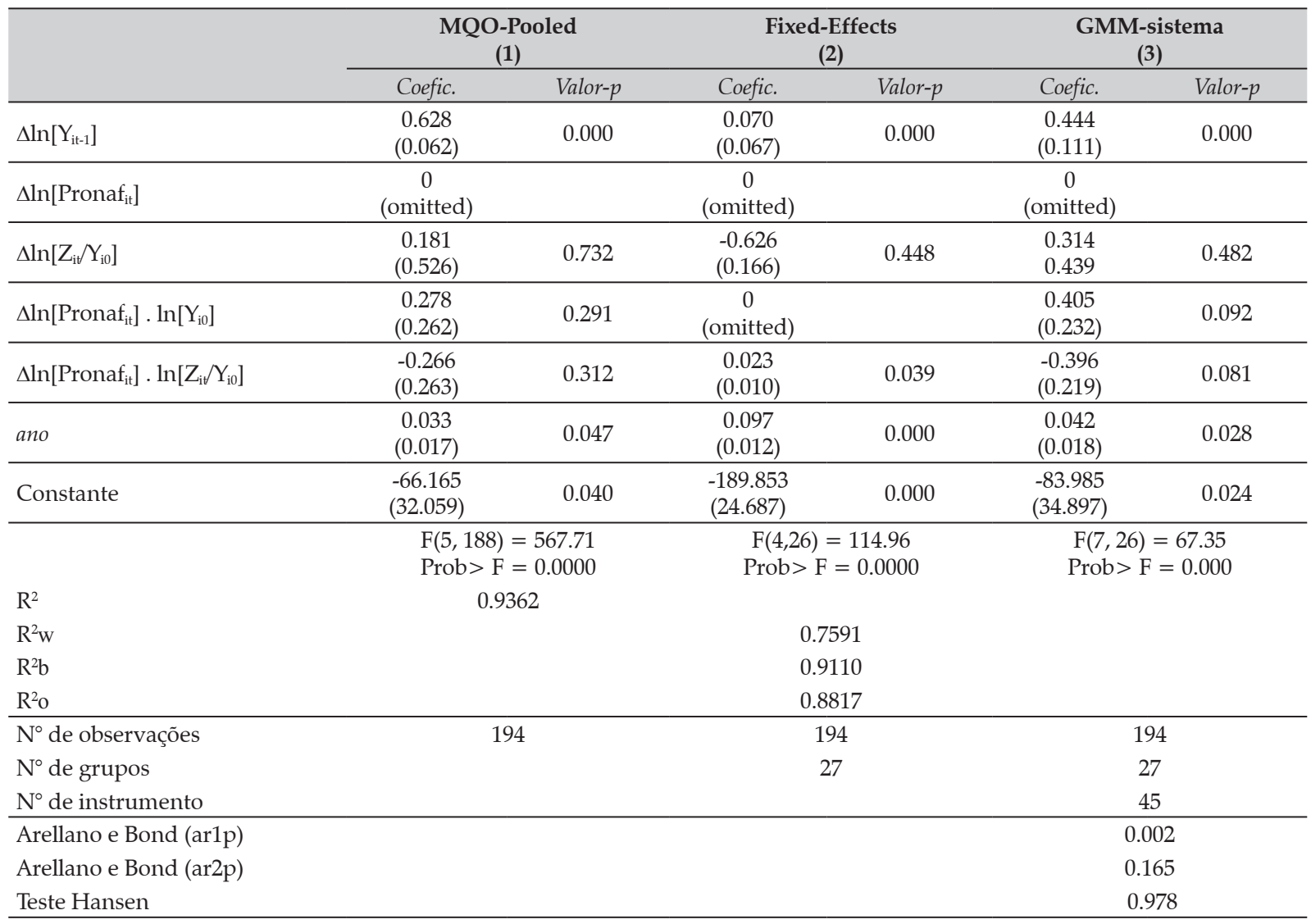

Fonte: Elaboração dos autores a partir dos microdados da PNAD/IBGE (2001-2009) e da base de dados do Pronaf - Bacen (2012). 
Tabela 6. Análise de sinal: Elasticidade Pronaf - Desigualdade de renda

\begin{tabular}{|c|c|c|c|c|c|c|}
\hline & \multicolumn{2}{|c|}{$\begin{array}{l}\text { MQO-Pooled } \\
\text { (1) }\end{array}$} & \multicolumn{2}{|c|}{$\begin{array}{l}\text { Fixed-Effects } \\
\text { (2) }\end{array}$} & \multicolumn{2}{|c|}{$\begin{array}{c}\text { GMM-sistema } \\
\text { (3) }\end{array}$} \\
\hline & Coefic. & Valor- $p$ & Coefic. & Valor- $p$ & Coefic. & Valor- $p$ \\
\hline$\Delta \ln \left[\operatorname{Gini}_{\mathrm{it}-1}\right]$ & $\begin{array}{l}0.1845 \\
(0.074) \\
\end{array}$ & 0.014 & $\begin{array}{c}0.185 \\
(0.081) \\
\end{array}$ & 0.022 & $\begin{array}{c}0.342 \\
(0.203) \\
\end{array}$ & 0.104 \\
\hline$\Delta \ln \left[\right.$ Pronaf $\left._{\mathrm{it}}\right]$ & $\begin{array}{l}-0.343 \\
(0.076) \\
\end{array}$ & 0.000 & $\begin{array}{l}-0.324 \\
(0.082) \\
\end{array}$ & 0.000 & $\begin{array}{l}-2.132 \\
(0.939) \\
\end{array}$ & 0.032 \\
\hline$\Delta \ln \left[Z_{\mathrm{it}} / Y_{\mathrm{i} 0}\right]$ & $\begin{array}{c}0 \\
\text { (omitted) } \\
\end{array}$ & & $\begin{array}{c}0.019 \\
(0.022) \\
\end{array}$ & 0.384 & $\begin{array}{c}0.562 \\
(0.259) \\
\end{array}$ & 0.039 \\
\hline$\Delta \ln \left[\right.$ Pronaf $\left._{\mathrm{it}}\right] . \ln \left[\mathrm{G}_{\mathrm{i} 0}\right]$ & $\begin{array}{c}0.317 \\
(0.069) \\
\end{array}$ & 0.000 & $\begin{array}{c}0.317 \\
(0.080) \\
\end{array}$ & 0.000 & $\begin{array}{c}2.166 \\
(0.941) \\
\end{array}$ & 0.030 \\
\hline$\Delta \ln \left[\right.$ Pronaf $\left._{\mathrm{it}}\right] . \ln \left[\mathrm{Z}_{\mathrm{it}} / Y_{\mathrm{i} 0}\right]$ & $\begin{array}{c}0.019 \\
(0.017) \\
\end{array}$ & 0.260 & $\begin{array}{c}0 \\
\text { (omitted) }\end{array}$ & & $\begin{array}{c}0 \\
\text { (omitted) } \\
\end{array}$ & \\
\hline ano & $\begin{array}{l}-0.006 \\
(0.003) \\
\end{array}$ & 0.042 & $\begin{array}{l}-0.006 \\
(0.003) \\
\end{array}$ & 0.033 & $\begin{array}{l}-0.034 \\
(0.014) \\
\end{array}$ & 0.020 \\
\hline \multirow[t]{2}{*}{ Constante } & $\begin{array}{l}11.056 \\
(5.582) \\
\end{array}$ & 0.049 & $\begin{array}{l}11.056 \\
(5.405) \\
\end{array}$ & 0.041 & $\begin{array}{c}69.395 \\
(28.039) \\
\end{array}$ & 0.020 \\
\hline & \multicolumn{2}{|c|}{$\begin{array}{c}F(5,188)=16.41 \\
\text { Prob }>F=0.0000\end{array}$} & \multicolumn{2}{|c|}{$\begin{array}{c}\text { W.chi } 2(5)=45.26 \\
\text { Prob }>\text { chi } 2=0.000\end{array}$} & \multicolumn{2}{|c|}{$\begin{array}{c}\mathrm{F}(6,26)=3.44 \\
\text { Prob }>\mathrm{F}=0.012\end{array}$} \\
\hline $\mathrm{R}^{2}$ & \multicolumn{2}{|c|}{0.3038} & \multirow{2}{*}{\multicolumn{2}{|c|}{0.0088}} & & \\
\hline $\mathrm{R}^{2} \mathrm{w}$ & & & & & & \\
\hline $\mathrm{R}^{2} \mathrm{~b}$ & & & \multicolumn{2}{|c|}{0.6587} & & \\
\hline $\mathrm{R}^{2} \mathrm{O}$ & & & \multicolumn{2}{|c|}{0.3038} & & \\
\hline $\mathrm{N}^{\circ}$ de observações & & & \multicolumn{2}{|c|}{194} & \multicolumn{2}{|c|}{194} \\
\hline $\mathrm{N}^{\circ}$ de grupos & & & \multicolumn{2}{|c|}{27} & \multicolumn{2}{|c|}{27} \\
\hline $\mathrm{N}^{\circ}$ de instrumento & & & & & \multicolumn{2}{|c|}{17} \\
\hline Arellano e Bond (ar1p) & & & & & \multicolumn{2}{|c|}{0.012} \\
\hline Arellano e Bond (ar2p) & & & & & \multicolumn{2}{|c|}{0.483} \\
\hline Teste Hansen & & & & & \multicolumn{2}{|c|}{0.334} \\
\hline
\end{tabular}

Fonte: Elaboração dos autores a partir dos microdados da PNAD/IBGE (2001-2009) e da base de dados do Pronaf - Bacen (2012).

estimação devido à inclusão da variável dependente defasada em um período entre as variáveis explicativas, além da presença dos efeitos fixos não observáveis. Entretanto, a mesma conclusão não pode ser aplicada para a estimação em GMM-Sistema de $\Delta \ln \left[\mathrm{Gini}_{\mathrm{it}-1}\right]$, que não apresentou significância estatística ao nível de $10 \%$, nem se posicionou entre os coeficientes desta mesma variável nos outros dois estimadores.

A análise de sinal da Tabela 5 apresenta insignificância estatística apenas para a variável de interação da relação inversa do nível de desenvolvimento inicial: $\Delta \ln \left[\mathrm{Z}_{\mathrm{i}} / Y_{\mathrm{i} 0}\right]$. Para a variável dependente defasada, observa-se que a renda per capita média rural tende a ser positivamente influenciada pela renda do período anterior. A variável de interação entre o Pronaf e a renda per capita média inicial, $\Delta \ln \left[\right.$ Pronaf $\left._{\mathrm{it}}\right] . \ln \left[\mathrm{Y}_{\mathrm{i} 0}\right]$, leva a crer que a elevação do montante dos créditos do Pronaf concedidos aos grupos A, B e A/C sobre a renda per capita média no rural brasileiro é tanto maior quanto maior a renda per capita média inicial da unidade federativa observada. Ou seja, os créditos do Pronaf apresentam efeito maior na renda entre as unidades federativas mais ricas quando $t=0$.

O sinal negativo da variável de interação entre o Pronaf e o inverso do nível inicial de desenvolvimento, $\Delta \ln \left[\right.$ Pronaf $\left._{\mathrm{it}}\right] \cdot \ln \left[\mathrm{z}_{\mathrm{i} i} / Y_{\mathrm{i} 0}\right]$, indica que o efeito da elevação do crédito do Pronaf sobre a renda per capta média rural é tanto maior quanto menor o nível inicial de desenvolvimento da unidade de observação. Ou seja, o Pronaf tende a elevar mais a renda entre as unidades menos desenvolvidas.

A análise de sinal da elasticidade Pronaf desigualdade de renda (Tabela 6) indica que a 
elevação do crédito do Pronaf tende a reduzir a concentração de renda. Ademais, o coeficiente positivo para o inverso do nível inicial de desenvolvimento indica que quanto menor o inverso do desenvolvimento inicial, menor tende a ser a concentração de renda.

Quanto à variável de interação entre o Pronaf e a desigualdade inicial de renda, $\Delta \ln \left[\right.$ Pronaf $\left._{\mathrm{it}}\right]$ . $\ln \left[\mathrm{G}_{\mathrm{i} 0}\right]$, implica que o repasse dos créditos do Pronaf aos grupos A, B e A/C sobre a desigualdade de renda rural é maior entre as unidades federativas com maior desigualdade de renda. $\mathrm{O}$ que quer dizer que os créditos do Pronaf tendem a reduzir mais a desigualdade de renda nas unidades federativas com maior Índice de Gini inicial.

Além disso, para as estimativas das Tabelas 5 e 6, os testes de Arellano e Bond apontam para a rejeição da hipótese nula de ausência de autocorrelação de primeira ordem e aceitação da existência de autocorrelação de segunda ordem dos resíduos; e os valores-p do teste de Hansen permitem aceitar as hipóteses de que os instrumentos utilizados na estimação dos modelos são válidos.

\section{Considerações finais}

O objetivo deste trabalho foi identificar os efeitos do crédito do Pronaf (grupos A, B e A/C) sobre a variação da renda domiciliar per capita rural e da desigualdade de renda rural, no período 2001-2009, utilizando o modelo econométrico de dados em painel GMM-Sistema.

Para isto, foi corroborado o pressuposto de Borguignon (2002) para o meio rural brasileiro, de que uma elevação da renda e/ou um decréscimo da desigualdade de renda tendem a afetar, negativamente, a pobreza rural brasileira. Além, disso, os resultados apontaram que políticas voltadas para a redução da desigualdade rural tendem a ser mais eficientes para a redução da pobreza rural, em detrimento de políticas que promovam a elevação da renda rural.

Os resultados ainda apontaram que os empréstimos concedidos pelo Pronaf (grupos A, $\mathrm{B}$ e $\mathrm{A} / \mathrm{C}$ ) mostraram-se estatisticamente signifi- cativos para a elevação da renda domiciliar per capita e para a redução da desigualdade de renda mensurada pelo Índice de Gini. Além disto, constatou-se que o efeito do Pronaf sobre estas variáveis é heterogêneo entre as unidades de observação, ao passo que seu efeito guarda relações com as características socioeconômicas das unidades da federação.

Portanto, indiretamente, o Pronaf (grupos A, B e A/C) é também um dos mecanismos de política pública que explica a redução da pobreza rural no período 2001-2009 ao promover o aumento e a redistribuição da renda rural.

\section{Referências bibliográficas}

ABRAMOVAY, R. Laços financeiros na luta contra a pobreza - FAPESP/Annablume. São Paulo, 2004.

ADAMS, R. J. Economic Growth, Inequality, and Poverty: Findings From a New Dataset. World Bank Policy Research Working Paper n. 2972, Washington, D.C., 2002.

ANDERSON, T. W. e HSIÃO, C. Estimation of dynamic models with error components. Journal of the American Statistical Association, 1981, p. 589-606.

ARAUJO, E. e MARINHO, J. Crescimento econômico e concentração de renda: seus efeitos na pobreza no Brasil. Associação Nacional dos Centros de pós-graduação em Economia, Série WorkingPaper BNDES/ANPEC, n. 24. Niteroi, 2012.

ARELLANO, M. e BOVER, O. Another look at the instrumental-variable estimation of error-components models. Journal of Econometrics, v. 68, n. 1, p. 29-52, 1995.

AQUINO, J. R. e SCHNEIDER, S. (Des)Caminhos da Política de Crédito do Proaf na luta contra a Pobreza e a Desigualdade Social no Brasil Rural. I Conferência Nacional de Políticas Públicas contra a Pobreza e a Desigualdade. Natal, 2010.

BALTAGI, B. H. Econometric Analysis of Panel Data. Wiley, Chichester, UK, 2001.

Banco Central do Brasil. FAQ - Programa Nacional de Fortalecimento da Agricultura Familiar - PRONAF. Base de dados. Disponível em: < http://www.bcb.gov. br/?PRONAFFAQ > . Acesso em: 13 fev. 2013.

BARROS, R. P., HENRIQUES, R. e MENDONÇA, R. Desigualdade e pobreza no Brasil: retrato de uma 
estabilidade inaceitável. Rev. Bra. Ciências Sociais, v. 15, n. 42,2000 .

BATISTA, H. R. Ensaios sobre a redução da pobreza rural no Brasil: contexto histórico, definições e estimativas. Dissertação de Mestrado, IE-UFU, Uberlândia, 2014.

BAUM, C. F. An Introduction to Modern Econometrics Using Stata. TX: Stata Press. College Station, 2006.

BLUNDELL, R. W. e BOND, S. R. Initial conditions and moment restrictions in dynamic panel data models. Journal of Econometrics, v. 87, p. 115-143, 1998.

BRADSHAW, J. e FINCH, N. Overlaps in dimensions of poverty. Journal of Social Policy, v. 32 n. 4, p. 513-525, Cambridge University Press, 2003.

BRASIL. Ministério da Agricultura e do Abastecimento. PRONAF - Programa Nacional de Fortalecimento da Agricultura Familiar. Brasília, 1996.

Ministério do Desenvolvimento Agrário - Secretaria de Agricultura Familiar. Disponível em: <http://www.mda.gov.br/portal/saf/programas/ pronaf $>$. Acesso em: 12 jan. 2013.

- Ministério do Desenvolvimento Agrário PRONAF - Condições do Crédito Rural - Plano Safra 2014/2015. Disponível em: <http://www.mda.gov.br/ sitemda/sites/sitemda/files/user_img_19/Tabela\% 20 com $\% 20$ condi $\%$ C $3 \%$ A $7 \%$ C $3 \%$ B 5es $\% 20$ do $\% 20$ Pronaf\%202014-2015.pdf>. Acesso em: 18 set. 2014.

Decreto № 1.946, de 28 de junho de 1996. Disponível em: < http://www.planalto.gov.br/ccivil_03/ decreto/D1946.htm >. Acesso em: 20 dez. 2012.

BOURGUIGNON, F. The Social Consequences of Economic Growth. In: AGHION, P. e DURLAUF, S. (Eds.). The Handbook of Economic Growth. Amsterdam: Elsevier, 2004.

The growth elasticity of poverty reduction: explaining heterogeneity across countries and time periods. In: EICHER, T. e S. Turnovsky, inequality and growth: theory and policy implications. Cambridge: The MIT Press, 2002.

CASTELAR, P. U. C., TABOSA, F. J. S. e IRFFI, G. D. Impacto do crescimento econômico e da desigualdade de renda do Brasil. XIX Fórum de Economia do Banco do Nordeste de Desenvolvimento. In: XVIII Encontro Regional de Economia.Fortaleza-CE, 2013.

CHEN, S. e WANG, Y. China's growth and poverty reduction: trends between 1990 and 1999. (Policy research working paper; 2651). World Bank. Washington, DC, 2001.
CLAESSENS, S. e PEROTTI, E. The links between finance and inequality: channels and evidence. WDR Background Paper on Asset Inequality and Agricultural Productivity. University of Amsterdam. Amsterdan, 2005.

CLINE, W. R. Trade policy and global poverty. Institute for International Economic, 344p.Washington D.C, 2004.

CONTRERAS, D. Poverty and inequality in a rapid growth economy: Chile 1990-96. Journal of Development Studies, v. 39, n. 3, p. 181-200, 2003.

DATT, G. e RAVALLION, M. Growth and redistribution components of changes in poverty measures: a decomposition with applications to Brazil and India in the 1980s. Journal of Development Economics, n. 38, p. 275-295, 1992.

DEDECCA, C. S. Uma abordagem multidimensional da pobreza rural Segundo a perspectiva da política pública. In: BUAINAIN, A. M. et al. A nova cara da pobreza rural: desafio para as políticas públicas. IICA, Brasília, 2012. (Série desenvolvimento rural sustentável, v. 16).

DELGADO, N., LEITE, S. P. e WESZ, V. J. Nota técnica sobre financiamento rural no Brasil. Observatório de Políticas Públicas para a Agricultura. Programa de Pósgraduação de Ciências Sociais em Desenvolvimento, Agricultura e Sociedade. UFRJ: Rio de Janeiro, 2011.

FAVERO, L. e ALVES, F. J. Análise de Desempenho do Programa Nacional de Fortalecimento da Agricultura Familiar - PRONAF em Pernambuco. In: Congresso SOBER. Passo Fundo - RS, 2002. (CD-ROM).

FECAMP - Fundação de Economia de Campinas e Convênio Pct/Iica-PRONAF. Estudos de Caso em Campo para Avaliação dos Impactos do Pronaf. Campinas, 2002. Disponível em: <www.pronaf.gov.br>.

FEIJÓ, R. The impact of a family farming credit programme on the rural economy of Brazil. In: Anais da ANPEC, XXIX Congresso de Economia. Salvador, 2001.

FERNANDES, F. F. Programa Nacional de Fortalecimento da Agricultura Familiar (PRONAF): análise da distribuição dos recursos entre 1999 e 2009. Dissertação de Mestrado, PPGE/IE-UFU, Uberlândia, 2011.

FERRAZ, O. G. et al. Microcrédito rural: análise sobre a modalidade do Pronaf B. In: XLVI Congresso da Sociedade Brasileira de Economia, Administração e Sociologia Rural. Rio Branco, 2008 (CD-ROM).

GAFAR, J. Growth, inequality and poverty in selected Caribbean and Latin America countries, with emphasis on Guyana. Journal of Latin America Studies, v. 30, p. 591617, 1998. 
GAIGER, F. As políticas de transferência de renda e a pobreza rural. Instituto Interamericano de cooperação para a agricultura (IICA).V Fórum Internacional de Desenvolvimento Territorial. Brasília, 2011.

HELFAND, S. M. e ROCHA, R. Pobreza e desigualdade de renda no Brasil rural: uma análise da queda recente. Disponível em: <http://economics.ucr.edu/people/ faculty/helfand/papers/2.\%20Helfand $\% 20$ et $\% 20$ al $\% 20$ Rural\%20Poverty\%207-2008.pdf>. Acesso em: 18 jul. 2013.

HOFFMANN, R.Transferência de renda e a redução da desigualdade no Brasil e cincos regiões entre 1997 e 2004. Econômica, v. 8, n. 1, p. 55-81, Rio de Janeiro, 2006.

HOFFMANN, R. e NEY, M. G. Desigualdade, escolaridade e rendimentos na agricultura, indústria e serviços, de 1992 a 2002. Economia e Sociedade, v. 13, n. 2 (23), p. 51-79, jul./dez. 2004.

IBGE - INSTITUTO BRASILEIRO DE GEOGRAFIA E ESTATÍSTICA. Censo Agropecuário 2006: agricultura familiar - Primeiros resultados - Brasil, Grandes Regiões e Unidades da Federação. Rio de Janeiro, 2009.

Pesquisa Nacional por Amostra de Domicílios. Disponível em: <http://www.ibge.gov.br/home/ estatistica/pesquisas/pesquisa_resultados.php?id_ pesquisa $=40>$. Acesso em: 20 out. 2012.

Índices de Preços ao Consumidor-IPCA/INPC. Disponível em: <http://www.ibge.gov.br/home/ estatistica/indicadores/precos/inpc_ipca/defaulttab. shtm >. Acesso em: 20 out. 2012.

IPEA - Instituto de Pesquisa Econômica Aplicada. Mudanças recentes na pobreza brasileira. Comunicados do IPEA, n 111. Brasília, 2011.

- Caracterização do Público Potencial do PRONAF "B" na Região Nordeste e no Estado de Minas Gerais: Uma análise baseada nos dados do Censo Agropecuário 2006. Relatório de Pesquisa. Brasília: IPEA, 2013. Disponível em: <http://www.ufrgs.br/pgdr/arquivos/resultpesq/1. pdf> . Acesso em: 17 set. 2014.

KAGEYAMA, A. Produtividade e renda na agricultura familiar: efeitos do PRONAFCrédito. Agricultura, v. 50, n. 2, p. 1-13, 2003.

MARTINS, A. J., ALENCAR, J. R. e MENDONÇA, E. C. O crédito do Programa Nacional de Fortalecimento da Agricultura Familiar (PRONAF) e a eficiência técnica agrícola brasileira: uma análise para o período de 1996 a 2003. In: XLIV Congresso SOBER. Fortaleza, 2006.(CD-ROM).

MATTEI, L. Impactos do Pronaf: análise de indicadores. MDA/NEAD (NEAD Estudos, 11). Brasília, 2005.
MATTEI, L. et al. Uma análise dos impactos do PRONAF sobre as economias locais nas regiões Nordeste, Sudeste e Norte do Brasil. In: do XLV Congresso da Sociedade Brasileira de Economia, Administração e Sociologia Rural. Londrina, 2007. (CD-ROM).

NERI, M. Desigualdade, Estabilidade e Bem-estar Social. Ensaios Econômicos, FGV; n. 637, Rio de Janeiro, 2006.

PEREIRA, S., FIGUEIREDO, A. e LOUREIRO, R. Avaliação da Política de Agricultura Familiar: uma abordagem de efeito-fixo. In: XVII Congresso da Sociedade Brasileira de Economia, Administração e Sociologia Rural.Cuiaba, 2004. (CD-ROM).

PUCCI, M. P. O PRONAF b e a pobreza rural do município de Caucaia, Estado de Ceará. Dissertação de mestrado. Curso de Mestrado Profissional de Avaliação em Políticas Públicas, Universidade Estadual de Ceará. Fortaleza, 2009.

RAVALLION, M. Poverty Comparisons: a Guide to Concepts and Methods. The World Bank, Working Paper, n. 88, Washington, DC, 1994.

Can High-Inequality Developing Countries Escape Absolute Poverty? Economic Letters, v. 56, p. 51-57, 1997.

. Pro-poor growth: a primer. World Bank Policy Research, Working Paper, n. 3242, 2004.

RICCI, R. et al. Relatório da pesquisa de análise da execução do Programa Nacional de Fortalecimento da Agricultura Familiar (PRONAF) em Minas Gerais. Belo Horizonte: Lumen/Instituto de Pesquisas-PUC/MG. 1997.

ROCHA, S. Pobreza e indigência no Brasil: algumas evidências empíricas com base na PNAD 2004. Nova economia, v. 16, n. 2, p. 265-299, 2006.

SEBRAE. Cartilha de acesso ao Pronaf 2011/2012. Disponível em: <http:/www.biblioteca.sebrae.com.br/ bds/bds.nsf/F8D5FB4FAB4789938325771C0068DA07/\$F ile/NT00044052.pdf> . Acesso em: 25 set. 2012.

SEN, A. K. The economics of life and death. Scientific American, p. 18-25, maio 1993.

. Sobre ética e economia. São Paulo: Companhia das Letras, 1999.

SCHNEIDER, S. e AQUINO, J. (Des)caminhos da política de crédito do PRONAF na luta contra pobreza e a desigualdade social no Brasil rural. Anais, In: I Conferência Nacional de Políticas Públicas contra a Pobreza e a Desigualdade. UFRN, v. 1. p. 1-21. Natal, 2010. 
SILVA, F. F., CORREA, V. P. e NEDER, H. D. Estudo comparativo da distribuição de recursos do PRONAF Crédito e Infra-estrutura, nas regiões Sul e Nordeste do Brasil: uma abordagem estatística. In: ORTEGA, A. C. e ALMEIDA FILHO, N. (Org.). Desenvolvimento Territorial, Segurança Alimentar e Economia Solidária. Campinas: Alínea, 2007, p. 123-158.

SILVA, S. P. e ALVES, E. F. Impactos Econômicos do Pronaf em Territórios Rurais: um estudo para o médio Jequitinhonha - MG. Disponível em: <http://www. bnb.gov.br/projwebren/exec/artigoRenPDF.aspx?cd artigo_ren $=1145>$. Acesso em: 01 abr. 2013.
SOUZA, P. M., NEY, M. G. e PONCIANO, N. J. Comportamento da distribuição dos financiamentos do Pronaf entre as unidades da federação, no período de período de 1999 a 2009. In: XLVIII Congresso da SOBER. Campo Grande, 2010.(CD-ROM).

TOCHETTO, D. G. et al. Crescimento pró-pobre no Brasil- uma análise exploratória. Anais do XXXII ENCONTRO NACIONAL DE ECONOMIA. João Pessoa, 2004.

ZAULI, E. M. Gastos sociais, pobreza e desigualdade de renda no Brasil. Revista Pensar BH - Politica Social, n. 13, p. 10-16, Belo Horizonte, set./nov. 2005. 